\title{
Caffeine has a small effect on 5 -km running performance of well-trained and recreational runners
}

\author{
Matthew P. O'Rourke a , Brendan J. O'Brien ${ }^{\mathrm{a}, *}$, \\ Wade L. Knez ${ }^{b}$, Carl D. Paton ${ }^{c}$ \\ a School of Human Movement and Sport Sciences, University of Ballarat, Australia \\ ${ }^{\mathrm{b}}$ Institute of Sport and Exercise Science, James Cook University, Australia \\ c Centre for Sport and Exercise Science, Hamilton, New Zealand
}

\author{
KEYWORDS \\ Caffeine; \\ Running performance; \\ Endurance
}

\begin{abstract}
Summary The purpose of this study was to investigate if caffeine ingestion improves $5-\mathrm{km}$ time-trial performance in well-trained and recreational runners. Using a double-blind placebo-controlled design, 15 well-trained and 15 recreational runners completed two randomized $5-\mathrm{km}$ time-trials, after ingestion of either $5 \mathrm{mg} \mathrm{kg}^{-1}$ of caffeine or a placebo. Caffeine ingestion significantly improved $5-\mathrm{km}$ running performance in both the well-trained and recreational runners. In comparison to the placebo trial, the caffeine trial resulted in $1.1 \%(90 \% \mathrm{Cl} 0.4-1.6)$ and $1.0 \%(0.2-2 \%)$ faster times for the well-trained and recreational runners. Reliability testing of the recreational runners indicated a test-retest error of measurement of $1.4 \%$. We conclude that caffeine ingestion is likely to produce small but significant gains in 5-km running performance for both well-trained and recreational runners.

(c) 2007 Sports Medicine Australia. Published by Elsevier Ltd. All rights reserved.
\end{abstract}

\section{Introduction}

Numerous studies have established that ingestion of caffeine improves performance in low-intensity endurance events lasting several hours. ${ }^{1}$ It would appear that caffeine ingestion also enhances performance during single efforts of short-duration high-intensity exercise ${ }^{2}$ and during repeated sprint

\footnotetext{
* Corresponding author.

E-mail address: b.obrien@ballarat.edu.au (B.J. O’Brien).
}

exercise. ${ }^{3}$ However, there have been few studies of the effects of caffeine on shorter duration (10-30 min) high-intensity endurance exercise. In a recent study, Bridge and Jones reported that caffeine improved performance in an $8-\mathrm{km}$ run by $\sim 1.3 \% .{ }^{4}$ Whether caffeine has a similar effect on running performance over shorter distances, such as $5 \mathrm{~km}$ is unclear. A number of athletes competing in 5-km racing regularly consume caffeine with little scientific rationale for its ergogenic benefits at this distance. Therefore, the intention of this 
study was to determine caffeine's effect on 5-km running performance with both well-trained and recreational runners.

\section{Methods}

\section{Participants}

The participants in the study comprised two groups: a well-trained runners group and a recreational runners group. The well-trained group consisted of 15 participants (mean \pm S.D.: age $32.2 \pm 8.8 \mathrm{y}$, body mass $68.9 \pm 6.1 \mathrm{~kg}$ ) with at least five years clublevel competition experience and the recreational runners consisted of 15 participants (age $29.0 \pm 5.7$ $y$, body mass $71.8 \pm 13.6 \mathrm{~kg}$ ), most with a history of playing team-sports, such as hockey. All participants satisfied medical pre-screening criteria and gave written informed consent to participate in this experiment, which was approved by the University of Ballarat Ethics Committee. None of the participants was considered to be a habitual caffeine consumer. Within $24 \mathrm{~h}$ prior to participation, in each treatment, the participant was requested to eat approximately $8-10 \mathrm{~g}$ of carbohydrate per $\mathrm{kg}$ of body weight, sleep a minimum of $7 \mathrm{~h}$, and drink enough fluid to ensure urine was clear in the hours preceding the $5-\mathrm{km}$ time trail. Furthermore, participants were asked to refrain from caffeine ingestion and strenuous exercise $48 \mathrm{~h}$ prior to all 5 - $\mathrm{km}$ time-trials.

\section{Procedure}

The recreational runners initially completed a 5$\mathrm{km}$ time-trial around a $400 \mathrm{~m}$ athletics track at the Domain Athletics Centre (Hobart) to familiarise themselves with the performance test. Participants were required to undertake a standardised warmup procedure prior to the trial. The warm up consisted of low to moderate cardiovascular exercise and stretching for approximately $10-15 \mathrm{~min}$. All participants were encouraged to provide their maximal effort, with recording of all participant 5-km completion times, documented and not discussed. The well-trained runners did not complete this familiarisation trial but all were experienced $5-\mathrm{km}$ runners and had completed a similar maximal 5-km effort within the previous three months. Two weeks after familiarisation, participants reconvened for the first of two 5-km time-trials. On assembly, each participant was randomly administered either $5 \mathrm{mg} \mathrm{kg}^{-1}$ of caffeine or placebo drug. The caffeine tablets consisted of No Doz ${ }^{\circledR}$, containing $100 \mathrm{mg}$ of caffeine per tablet, while the placebo constituted sugar formulated tablets. Tablets were administered as whole and/or partial tablets dependent on the individual's body mass and intake required. The standardised warmup performed in the familiarisation was completed prior to the $5-\mathrm{km}$ time-trial. There was a period of one hour in duration between substance ingestion and the commencement of the 5-km time-trial. Participants were encouraged to produce a maximal effort and times were recorded manually using a stopwatch to the nearest second. Recorded times for all participants were documented and not discussed with the participants until completion of all trials. Participants completed both treatments at the same approximate time of day.

\section{Statistical analyses}

Simple group statistics are shown as means \pm between-subject standard deviations. Differences in the effect of caffeine on performance in both groups (pooled data) were initially determined via a two-way ANOVA with the level of significance set at $p<0.05$. Additionally, the magnitude of the effect of caffeine on performance was estimated with an Excel spreadsheet ${ }^{5}$ in accordance with the recent recommendations of Batterham and Hopkins ${ }^{6}$. The mean effect of caffeine and its $90 \%$ confidence limits $(\mathrm{Cl})$ were estimated using the unequal-variances, $t$ statistic, computed for change scores between placebo and caffeine treatments in each of the two groups. In order to control for difference in ability between subjects, each subject's change score was expressed as a percent of baseline score via analysis of log-transformed values, to reduce any bias arising from non-uniformity of error. The error of measurement, expressed as a coefficient of variation, was also estimated with the spreadsheet for the recreational group by comparing subjects' familiarisation trials with their placebo experimental condition.

\section{Results}

Caffeine ingestion significantly $(p<0.01)$ enhanced performance in the $5-\mathrm{km}$ running test. Twentyseven of the 30 runners gained a performance benefit from caffeine ingestion. In addition, while well-trained subjects were significantly $(p<0.01)$ faster than recreational subjects, there was no interaction between caffeine's effect and the subject's training (well-trained versus recreational) status. Times to complete the $5 \mathrm{~km}$ for the welltrained group were $1058 \pm 68 \mathrm{~s}$ versus $1047 \pm 69 \mathrm{~s}$ 
for placebo and caffeine trials respectively. The recreational group were $\sim 20 \%$ slower than the well-trained group, recording times of $1298 \pm 84 \mathrm{~s}$ versus $1286 \pm 86 \mathrm{~s}$ for placebo and caffeine trials respectively. The magnitude of performance enhancement in the $5-\mathrm{km}$ trial following caffeine ingestion was similar for both groups and equivalent to $1.0 \%(\mathrm{Cl} 0.4-1.6 \%)$ for the well-trained runners and $1.1 \%(\mathrm{Cl} 0.2-2 \%)$ for the recreational runners. Reliability testing of the recreational runners indicated a test-retest error of measurement of $1.4 \%$.

\section{Discussion}

The present study revealed that ingestion of $5 \mathrm{mg} \mathrm{kg}^{-1}$ of body mass $1 \mathrm{~h}$ prior to a $5-\mathrm{km}$ running time-trial significantly enhances performance by decreasing the time to completion in both recreational and well-trained runners. Additionally, well-trained and recreational runners experienced similar benefits following caffeine ingestion $(\sim 1 \%)$ on 5-km running performance; therefore the mechanism by which caffeine affects performance appears unaffected by training status.

Our study provides additional support for Bridges and Jones, ${ }^{4}$ who reported that caffeine enhanced running speed in an $8-\mathrm{km}$ event by $\sim 1.3 \%$. The mechanism(s) by which caffeine elicits its performance-enhancing properties in these shortduration high-intensity events is still open to speculation; however, possible suggested mechanisms include increased fat oxidation, ${ }^{7}$ enhanced central nervous system activity and decreased perception of pain, ${ }^{8}$ and attenuation of the elevation in extracellular $\mathrm{K}^{+}$concentration. ${ }^{9}$ It is unlikely, however, that the proposed mechanism of caffeine ingestion of increasing fatty acid oxidation and reducing glycogenolysis ${ }^{7}$ contributed to the superior performance in the caffeine treatments in the present study, as glycogen levels are unlikely to be a limiting factor in $5-\mathrm{km}$ running performance ${ }^{1}$. The more likely mechanisms of caffeine-enhancing cellular potassium regulation or favourable central nervous system alterations warrant further scientific investigation.
While our results revealed that caffeine ingestion is likely to improve $5-\mathrm{km}$ performance, it is debatable whether or not a $1 \%$ improvement in completion time would be considered a worthwhile enhancement, especially in non-elite runners given that the test-re-test error for this group was $1.4 \%$. However a previous study ${ }^{10}$ suggests that the smallest worthwhile gain in performance time is $\sim 1 \%$ for well-trained runners and therefore caffeine may offer a worthwhile advantage for these athletes.

\section{Conclusion}

We conclude that caffeine ingestion is likely to produce significant but possibly small beneficial gains in 5-km running performance for both well-trained and recreational runners.

\section{References}

1. Graham TE. Caffeine and exercise: metabolism, endurance and performance. Sports Med 2001;31:785-807.

2. Anselme F, Collomp K, Mercier B, et al. Caffeine increases maximal anaerobic power and blood lactate concentration. Eur J Appl Physiol Occup Physiol 1992;65(2):188-91.

3. Paton C, Hopkins WG, Vollebregt L. Little effect of caffeine ingestion on repeated sprints in team-sport athletes. Med Sci Sports Exerc 2001;33(5):822-55.

4. Bridge CA, Jones MA. The effect of caffeine ingestion on $8-\mathrm{km}$ performance in a field setting. J Sport Sci 2006;24:433-9.

5. W.G. Hopkins. A spreadsheet for analysis of straightforward controlled trials. Sportscience 2003; 7: http://sportsci.org/jour/03/wghtrials.htm.

6. Batterham AM, Hopkins WG. Making meaningful inferences about magnitudes. Int J Sports Physiol Perf 2006;1:50-7.

7. Costill DL, Dalsky GP, Fink WJ. Effects of caffeine on metabolism and exercise performance. Med Sci Sports Exerc 1978;10:155-8.

8. Kalmar JM, Caffarelli E. Caffeine: a valuable tool to study central fatigue in humans? Exerc Sport Sci Rev 2004;32:143-7.

9. Lindinger MI, Graham TE, Spriet LL. Caffeine attenuates the exercise-induced increase in plasma $\left[\mathrm{K}^{+}\right]$in humans. J Appl Physiol 1993;74:1149-55.

10. Hopkins WG, Hewson DJ. Variability of competitive performance of distance runners. Med Sci Sports Exerc 2001;33(9):1588-92. 